\title{
Fronteras, identidades, metáforas
}

\author{
Stefano Arduini ${ }^{1}$
}

1.1. En los orígenes de la literatura europea existe una obra de Esquilo que representa la idea de frontera y la imagen del extranjero, me refiero a Los persas.

Se trata de la escena de Susa donde los viejos Consejeros y la reina Atosa, viuda de Darío y madre de Jerjes, se preguntan por el destino de la armada que ha partido a la guerra contra los griegos. La reina ha tenido un sueño premonitorio que la ha perturbado. Pero el sueño se confirma cuando reciben a través de un mensajero la noticia de la derrota persa de Salamina, la masacre de los soldados en la isla de Psittalia y la fuga de Jerjes. Se evoca a Darío que preanuncia aún desgracias en Beocia y Platea. Con la desaparición del espectro entra Jerjes, herido y lloroso, que recuerda a todos los guerreros muertos y la destrucción de su ejército.

Esquilo representa la gran victoria griega de Salamina desde el lado del enemigo. Es, sin embargo, un extraño enemigo que parece tener las mismas tradiciones griegas, un extranjero que posee importantes características de un griego. El otro, por tanto, aquí no es del todo un extraño, es una figura de la frontera que, por ejemplo, habla en lengua griega. El dios persa es Zeus, nomos la ley, bárbaros se llaman a sí mismos los persas. No hay diversidad, el otro es visto como un semejante en el límite de una frontera. Es más bien una especie de híbrido. Es interesante advertir que ésta, que es la primera tragedia que nos llega, pone en escena un palacio extranjero oriental, del mismo modo que sucede con el primer poema, la Ilíada, y como sucede también con Herodoto que, en las Historias, narra la guerra de la Hélade contra los persas. Y es justamente en la frontera con

El profesor Arduini, de la Universidad de Urbino, Italia, visitó nuestra Facultad los días 10 y 11 de noviembre de 2003. Dio dos estimulantes conferencias, reproducimos aquí una versión corregida por el propio autor de la segunda de éstas. 
Oriente como se define por primera vez el concepto de alteridad. Es un encuentro de fronteras, el resultado de una hibridación. En la orilla de la costa asiática, los griegos están bajo el dominio de los persas, al tiempo que la cultura aqueménida está marcada por características griegas. Pero es ahí donde se definen los límites del nosotros. Y es precisamente en este espacio donde las culturas se mezclan, aunque se delimitan, donde las identidades parecen perfilarse marcando un dentro y un fuera.

1.2. Otra tragedia de Esquilo habla indirectamente de fronteras: se trata de Agamenón. El sacrificio de la hija Ifigenia es consecuencia de la ofensa que Agamenón ha hecho a Artemisa, la diosa hermana gemela de Apolo, hija de Zeus y de Leto, en ocasiones identificada con Selene y Hécate como personificación de la Luna. La Diana del panteón latino es diosa de la caza, protectora de los animales selváticos de las fuentes y los arroyos. Pero también es diosa que sana y salva, que protege a las muchachas en el parto. Diosa de los tránsitos. Como tal es salvadora, le evita a Ifigenia el sacrificio sustituyéndola por una cierva y llevándola a Táuride, donde se convertirá en una de sus sacerdotisas. Es una diosa con un nombre de origen no griego, tal vez asiático y, por lo tanto, diosa de la frontera, del límite, del mismo modo que su reino se sitúa en el confín del mundo. Y por ello es limnatis, porque es diosa de los espigones y de los litorales, de aquellos lugares que no son ni tierra ni mar. Figura híbrida, resultado de entrecruzamientos y superposiciones. La frontera que protege vuelve a Artemisa ambigua. Subraya la fragilidad del margen, pero confirma su intangibilidad, volviéndolo distinguible y reconocible.

Hay un gran libro de Seamus Heneay, The Spirit Level, donde Agamenón, la tragedia en nombre de Artemisa, aparece junto a un poema dedicado a Brígida, la santa irlandesa derivada de Brigid. Brigid es la diosa celta de la curación, del fuego, de los herreros, de la poesía, de la sabiduría y de la fecundidad; es protectora de los poetas, forjadores y sanadores. En su honor se celebra la fiesta de Imbolc, la fiesta del paso a la primavera, en la que se vertía leche sobre la tierra como símbolo de fertilidad. Del mismo modo que Artemisa es la diosa del tránsito, de la transformación y del límite. Brigid representa el margen, el que marca las existencias en la frontera, como Artemisa, como la propia cultura griega en sus orígenes, tierra de tránsito entre oriente y occidente, en la que las lenguas, los símbolos, las significaciones se desplazan continuamente en busca de una 
posibilidad de traducción. He aquí pues que Brígida, Artemisa, Santa Brígida, Diana, no son simplemente interpretaciones de universos culturales distintos, sino verdaderas y auténticas traducciones. Las diosas de los límites y las fronteras son dueñas de más territorios porque ponen en contacto culturas diversas que deben ser traducidas para ser comprendidas.

1.3. Un concepto de la dialectología estructural puede ayudarnos en este punto, transfiriéndolo al ámbito de los estudios culturales, el concepto de diasistema.

Tal concepto fue introducido por Uriel Weinrich, ${ }^{2}$ que lo interpretaba como una estructura lingüística resultado de variedades limítrofes, y que lo utilizó en el estudio del contacto y la interferencia lingüísticas. En este sentido, el diasistema nos permite interpretar esas zonas de sombra que son las fronteras lingüísticas, que subdividen un continuum en variedades discretas.

Es posible entender el diasistema ${ }^{3}$ como la zona en la cual más sistemas se oponen recíprocamente $\mathrm{y}$, en ciertos períodos históricos, tienden a entrar en contacto. En esta idea llama particularmente la atención el antagonismo que hace que un sistema ejerza una cierta presión sobre otro, obligando al segundo a reorganizarse teniendo en cuenta el primero. Así pues, precisamente en las zonas fronterizas, cuando dos sistemas entran en contacto, uno funciona como hegemónico y el otro como dominado. Esto significa, por consiguiente, que los dos sistemas no están equilibrados en un mismo plano. No obstante, también conviene recordar, como ha advertido Corrado Grassi, «que la acción desplegada por el sistema hegemónico sobre el dominado no conlleva siempre, como resultado, la simple identificación de éste con aquél». ${ }^{4}$ Se trata de una idea importante que nos induce a pensar que no hay tanto una simple adaptación de un sistema a otro, cuanto más bien una reacción del sistema no hegemónico que intenta resolver los desequilibrios creados por el contacto con el sistema hege-

Uriel Weinrich, Languages in Contact, La Haya, Mouton 1963.

Luigi HeILmanN, «Structuralisme et histoire dans le domaine linguistique italien: le vocalisme d'un dialecte typique», in Actes du IX Congrès Internationale de Linguistique et Philologie Romanes, III Paris 1965.

4 Corrado Grassi, «Il concetto di diasistema e i principi della geografia linguistica», in Atti del Convegno Internazionale sul tema: Gli Atlanti Linguistici. Problemi e risultati, Roma, Accademia Nazionale dei Lincei 1969: 271-283. 
mónico. Lo cual comporta, naturalmente, que no podamos entender los sistemas como un todo homogéneo y homologado, sino como un conjunto de posibilidades más bien diversas. ${ }^{5}$ Tal dinámica constituye la vitalidad de los sistemas lingüísticos, pero es extensible a los contactos de cualquier sistema cultural. Por ejemplo, el contacto entre las literaturas, donde por un lado una literatura es siempre hegemónica, pero por otro la dominada no se adapta simplemente a los esquemas de la primera y reacciona reorganizando el sistema o el polisistema.

1.4. De contactos y de fronteras entre culturas ha hablado Homi Bahbha ${ }^{6}$ a propósito de un tercer espacio de la enunciación que obliga a repensar la identidad histórica de una cultura como un todo homogéneo. Bhabha afirma que el proceso de interpretación no puede considerarse un sencillo proceso de comunicación entre un yo y un tú:

The production of meaning requires that these two places be mobilized in the passage through a Third Space, which represents both the general conditions of language and the specific implication of the utterance in a performative and institutional strategy of which it cannot 'in itself' be conscious. ${ }^{7}$

Como consecuencia, tal relación inconsciente conduce a una ambivalencia en la interpretación.

The pronominal I of the proposition cannot be made to address... the subject of enunciation, for this is not personable, but remains a spatial relation within the schemata and strategies of discourse. The meaning of the utterance is quite literally neither the one nor the other. $(i d .)^{8}$

5 Creo que sería interesante confrontar estas ideas con la obra de Antonio Cornejo Polar, cfr. Escribir en el aire. Ensayo sobre la heterogeneidad socio-cultural en las literaturas andinas, Lima, Editorial Horizonte 1994.

6 Homi K. Внавна, The Location of Culture, London and New York, Routledge 1994.

7 «La producción de significado requiere que estos dos lugares sean movilizados en el paso a través de un TERCER ESPACIO, que representa a la vez las condiciones generales del lenguaje y la implicación específica de la expresión en una estrategia performativa e institucional de la que no puede 'en sí mismo' ser consciente» id.: 36.

8 «La forma pronominal 'I' de la proposición no se puede hacer que se dirija... al sujeto de la enunciación, ya que éste no es personal, pero permanece una relación espacial dentro de los esquemas y estrategias del discurso. El significado de la expresión no es literalmente ni uno ni otro». 
Bhabha extrae consecuencias en el ámbito cultural, por cuanto la idea de Tercer Espacio rompe con la posibilidad de considerar el conocimiento cultural como un código unitario en evolución:

It is often taken for granted in materialist and idealist problematics that the value of culture as an object of study, and the value of any analytic activity that is considered cultural, lie in a capacity to produce a cross-referential, generalizable unity that signifies a progression or evolution of ideas-in-time, as well as a critical self-reflection on their premisses or determinants $(i d.){ }^{9}$

Sin embargo, la existencia de un Tercer Espacio de la enunciación, que ha permitido que aparezca la ambigüedad en el proceso de interpretación, nos dice que la identidad de una cultura no es algo homogéneo, que no existe pureza cultural.

Bhabha dice que los símbolos de una cultura no tienen una fijeza originaria y que son objeto de continuas reescrituras y traducciones. Un espacio móvil en continua reestructuración y búsqueda de equilibrio dinámico. Una identidad se construye entonces mediante sucesivos acopios que hacen difícil mostrar una sola cara. He aquí pues el concepto de hibridismo,,$^{10}$ unido al de frontera inestable, como identidad resultado de encuentros, superposiciones, revaloraciones. El hibridismo significa también cultura de frontera, colocándose sobre un espacio que está al mismo tiempo dentro y fuera, un no-lugar que es el resultado de continuas transferencias de significado y, por tanto, de traducciones. La identidad es justamente la consecuencia de estas continuas traducciones.

2.1. Al inicio de Los Persas, el Coro enumera a los jefes que han seguido a Jerjes y con ellos los pueblos que constituyen el imperio. Lo que Esquilo muestra es la multiplicidad como característica de la identidad persa. La característica del imperio persa, así pues, es estar constituido por diversos pueblos, razas, lenguas, religiones. La diversidad en él es la marca de reconocimiento. De este

«A menudo se da por seguro en la problemática materialista e idealista que el valor de la cultura es un objeto de estudio y que el valor de cualquier actividad analítica que sea considerada cultural reside en una capacidad de producir una unidad generalizable de referencias cruzadas que significa una progresión o evolución de las ideas en el tiempo, así como una autorreflexión crítica sobre sus premisas o determinantes».

10 Sobre la idea de hibridismo sobre todo en el contexto latinoamericano cfr. Néstor GARCíA Canclini, Culturas híbridas, 1. ${ }^{a}$ edición actualizada, Buenos Aires, Editorial Paidós 2001 
modo, la identidad griega se crea por contraste con los persas: aquéllos son múltiples, un conjunto de lenguas, tradiciones y culturas, mientras que los griegos son unidad, se consideran fuera del continuum asiático, para transformarse en una entidad discreta, convirtiendo en pertinentes algunos rasgos culturales y excluyendo otros. El diasistema cultural en el que viven muchos griegos se reconoce como perteneciente a un lado y a una identidad. Es una vía de autorrepresentación que pone en juego una narración. Los griegos se descubren a sí mismos y se reconocen en la narración del combate con el único imperio universal de la época.

2.2. Por consiguiente, tiene razón Stuart Hall, ${ }^{11}$ si bien él se refiere a la modernidad tardía, cuando escribe que las identidades no están unificadas y son el fruto de múltiples discursos y de prácticas sociales diferentes y antagónicas:

Las identidades, por tanto, se constituyen dentro y no fuera de la representación. Hacen referencia tanto a la invención de la tradición cuanto a la propia tradición... Las identidades nacen de la narrativización de sí mismas, pero la naturaleza necesariamente ficticia de tal proceso no destruye de ningún modo su eficacia discursiva, material o política, a pesar de que la pertenencia, 'la sutura en la historia' a través de la que se originan las identidades, se encuentra en parte en el imaginario (y en lo simbólico) y se construye así, en parte, en la fantasía, o al menos en un ámbito misterioso. ${ }^{12}$

En este sentido las identidades son más bien representaciones inestables que ponen en juego relaciones antagónicas en continua transformación. ${ }^{13}$ No nos hallamos, así pues, frente a esencias definidas, sino frente a la continua redefinición de fronteras y sistemas:

Las identidades son por lo tanto lugares de destino temporal para las posiciones del sujeto, que hemos construido a partir de las prácticas discursivas. ${ }^{14}$

Esto significa también que a menudo las identidades son el resultado inevitable de elecciones ideológicas que llevan consigo las prácticas discursivas. La

\footnotetext{
Stuart Hall, «A chi serve 'l'identità'?», en C. Bianchi, C. Demaria, S. Nergaard (ed.), Spettri del potere, Roma, Meltemi 2002:129-153.

id.: 134.

cfr. También Antonio Cornejo Polar, cit.

id.: 136.
} 
ideología guía las nociones de identidad porque, como ha subrayado Gayatri Chakravorty Spivak, no se puede salir de la ideología, del mismo modo que no se puede pretender salir de la retórica.

2.3. En esta dirección ha sido muy importante la noción de polisistema y la idea de que, en la creación de una identidad, las estrategias traductoras desempeñan un papel central. Con polisistema se pretende definir el conjunto de las actividades que, en el interior de una cultura, son interpretadas como literarias. En este sentido, el polisistema es un sistema de sistemas que conjuntamente constituyen la literatura, entendida como un sistema en movimiento con transformaciones y continuidad. Desde este punto de vista la literatura se concibe como una función de los juicios de valor que pertenecen a un período. Una literatura, además, no está aislada, sino que está sujeta a relaciones con otras literaturas, creando lo que Itamar Even-Zohar ${ }^{15}$ llama interferencias. Tales interferencias son inevitables en los contactos entre dos culturas y suelen ser unilaterales en la medida en que la literatura que es fuente desempeña este papel gracias a su prestigio y al hecho de que el sistema importador necesita hallar modelos que no encuentra en su interior. Las relaciones entre el interior y el exterior del sistema provocan una serie de oposiciones: la oposición entre textos canónicos y no canónicos; entre centro y periferia del sistema; entre innovación y conservación. El concepto de texto canónico es determinante para comprender cómo se transmiten ciertas marcas de identidad en el interior de una sociedad. Por ejemplo, la pertenencia al canon depende de la legitimación de los grupos culturales dominantes según modelos que cambian en el curso de los diversos contextos históricos. Unida al concepto de canonización está la distinción entre centro y periferia. El centro del sistema literario lo ocupan inevitablemente los textos canónicos, esto es, aquellos filtrados a través de la cultura oficial que han conseguido obtener la legitimación de la institución. También la oposición entre tradición e innovación está relacionada con el problema de la aceptación de una obra en un momento determinado y con el hecho de perfilarse una identidad cultural. La tradición, es decir, el repertorio estable que la constituye, es un sistema secundario, sus textos serán de un modo u otro predecibles y cualquier tentativa de disgregar tal estabilidad se considerará una agresión.

15 Itamar Even-Zohar, Polysystem Studies, número monográfico de Poetics Today, II, 1, 1990 . 
En cambio, el sistema innovador es un sistema primario, aquél en el que, por tanto, intervienen nuevos elementos y en el que se redefine un repertorio. ${ }^{16} \mathrm{Un}$ sistema puede ser estable o inestable según la capacidad de controlar y asimilar los cambios. En este contexto entra la literatura traducida como un sistema entre otros en el interior del polisistema literario. El polisistema receptor selecciona la literatura extranjera de acuerdo con las convenciones aceptadas por el mismo polisistema. Este filtro actuará de distinto modo según las condiciones del polisistema receptor: un polisistema estable tenderá a imponer sus propios modelos a las traducciones; y viceversa, un polisistema débil o inestable resultará influido por los modelos que importa.

En particular, la traducción, precisamente por cuanto es en esencia un medio para redefinir los propios límites culturales, asume un papel central en el interior de una cultura en tres situaciones sociales: cuando ésta es joven o en un proceso de estabilización, cuando es periférica o débil, o cuando está experimentando una crisis. En los dos primeros casos, la literatura traducida sirve para ocupar los vacíos del polisistema y crea a la vez una especie de dependencia de la literatura débil o periférica respecto de las centrales, en términos de sistema hegemónico y dominado. En el tercer caso, la literatura traducida puede asumir una función primaria incluso en las literaturas centrales. Se piensa en los momentos de transformación cultural cuando ya no es posible encontrar modelos en el interior de una cultura.

2.4. Podremos extraer algunas consecuencias de estos aspectos y afirmar, por ejemplo, que en la labor del traductor se puede observar mejor que en ninguna otra cómo la ideología desempeña un papel fundamental en la creación de una identidad. Se podría decir más bien que precisamente allí donde las elecciones parecen arbitrarias y propias de una estrategia puramente literaria, es donde se manifiestan las señas de cómo los grupos sociales se posicionan frente a la pertenencia a una cultura, raza o religión.

16 Itamar Even-ZoHAR, «La posizione della letteratura tradotta all'interno del polisistema letterario», en S. Nergaard (ed.), Teorie contemporanee della traduzione, Milano, Bompiani 1995: 225-238, 229. Cfr. también Gideon Toury, Descriptive Translation Studies and Beyond, Amsterdam-Philadelphia, Benjamins 1995. 
Puede ser útil recordar que en el origen del debate italiano sobre el romanticismo, y por tanto también del debate sobre la identidad nacional, hay precisamente un texto sobre la traducción. Me refiero naturalmente al texto de Madame de Staël, De l'esprit des traductiones, traducido en 1816 por Pietro Giordani con el título de Sobre la manera y la utilidad de las traducciones. El ensayo salía en Biblioteca Italiana, la primera revista postnapoleónica de un cierto relieve, con la que el gobernador austriaco Enrico de Bellegarde quería «velar por la opinión pública en Italia y rectificar muchos errores». No se puede negar que la finalidad era política y resulta interesante observar que el texto de inicio se refiriera a la traducción. De Staël parece haber leído los teóricos modernos. La cultura italiana está en crisis y sólo puede regenerarse a través de las traducciones:

En mi opinión, los italianos deberían traducir diligentemente muchos de los poemas ingleses y alemanes, con los que mostrar novedades a sus ciudadanos, los cuales, por lo general, están satisfechos con la antigua mitología, y no piensan que tales fábulas están un poco anticuadas, cuando incluso el resto de Europa ya las ha abandonado y olvidado.

El artículo atrajo una serie de intervenciones que, teniendo como tema la literatura, introducían implícitamente diversos apuntes sobre la que debiera ser la identidad cultural italiana, que había de renovarse completamente con el ejemplo de cuanto sucedía más allá de los Alpes o reencontrarse en un diálogo con el pasado. ${ }^{17}$ Sin embargo, lo que tenemos que subrayar es que el debate sobre la traducción iba a dibujar unos límites culturales que marcarían el romanticismo italiano en oposición a los otros romanticismos, en un momento en que el código tradicional de las reglas literarias se estaba transformando y debía repensarse no sólo en Italia, sino en toda Europa.

17 En el mes de abril de 1816, en la misma Biblioteca Italiana, Giordani (Un italiano responde al discurso de Staël) respondía acogiéndose a una tradición italiana que no debía mezclarse con la nórdica. Continúa con posiciones más mediadoras Ludovico Arborio Gattinara di Breme con tres intervenciones entre las que conviene recordar además de Sobre la injusticia de algunos juicios literarios italianos de 1816, las Observaciones sobre "Il Giaurr», relativas a la traducción del texto de Byron de Pellegrino Rossi en 1818. Sigue, todavía en 1816, Pietro Borsieri, con Aventuras literarias o Consejos de un hombre de bien a varios escritores. También de 1816 es la Carta semiseria de Crisóstomo a su hijo, con la traducción de dos baladas de Burger, de Giovanni Berchet. Finalmente, de Carlo Giuseppe Landonio, la Respuesta de un italiano a los dos discursos de Madame de Staël, también en 1816. 
La discusión italiana sobre el romanticismo es sólo uno de los ejemplos de cómo las estrategias literarias y las elecciones a la hora de traducir mantienen una estrecha relación con las opciones ideológicas de una época y desempeñan una función primaria en la determinación de identidades y fronteras. Los escritores y literatos italianos habían sido multilingües e híbridos desde sus orígenes. Pertenecientes a la koiné latina y vulgar al menos hasta finales del siglo XVI. Y después plurilingües e «intranacionales» hasta el XIX. En el s. XVII, Marino está en la corte de Luis XIII, Zeno y Metastasio son poetas de la corte en Viena. En el s. XVIII, Goldoni trabaja en la «Comédie», Alfieri escribe en francés, Foscolo vive en Londres y usa el inglés, para Manzoni la lengua familiar es el francés. Pero he aquí que el debate sobre las traducciones marca una frontera y una diferencia no ya sólo literaria, sino también nacional que trazará la cultura italiana subsiguiente. Si el literato italiano había sido hasta entonces un literato «en italiano», sin una marca nacional, tras la polémica sobre la traducción se convertirá en un literato «italiano», identificando una frontera que será también política.

3.1. Construir una identidad cultural significa construir una representación de la propia pertenencia respecto de lo pertinente de una frontera que se identifica en una zona diasistemática. Es el producto de una dialéctica hegemónicodominado y no el resultado de una naturalidad originaria. Las identidades no son un estatus fijado desde el punto de partida, sino que son el fruto de una elaboración socio-semiótica que se define por la relación con las demás identidades y en su encuentro con ellas. En principio, existe sólo un territorio confuso e híbrido que se especifica e identifica después, distinguiendo al otro del cual diferenciarse. Es una operación de delimitación de fronteras, que de culturales pasarán a ser políticas y nacionales.

En la delimitación de las fronteras lo simbólico y lo imaginario desempeñan un papel importante. Vuelvo a Stuart Hall:

Precisamente porque las identidades se construyen dentro y no fuera del discurso, es preciso considerarlas como resultado de estrategias enunciativas específicas, en un contexto histórico e institucional específicos, en el interior de formaciones y prácticas discursivas también específicas. ${ }^{18}$

$18 \quad I d:: 135$. 
Por lo tanto, las formas simbólicas que construimos en lo más profundo de una cultura revelan el modo en que tal cultura se construye e identifica con determinados valores.

3.2. En este sentido podríamos releer los trabajos sobre la metáfora de George Lakoff. ${ }^{19}$ Para Lakoff, la metáfora se refiere al pensamiento y no al lenguaje. En cuanto que elementos conceptuales, las metáforas forman parte del aparato cognitivo de una cultura y poseen algunas características que pueden sintetizarse del siguiente modo: son sistemáticas, son inconscientes, son generalizables, y son productivas y convencionalizadas en el lenguaje. Lakoff añade que si bien el lenguaje puede producir un número infinito de palabras metafóricas, en realidad las metáforas conceptuales existen en un número fijo y limitado, aunque se pueden combinar entre ellas. Lakoff enumera algunas metáforas generales y algunas metáforas conceptuales que se refieren al ámbito de la vida y de la muerte: metáforas generales: los objetivos son destinos, los acontecimientos son acciones; metáforas referidas a la vida y a la muerte: la vida es un viaje, la muerte es una partida, las personas son plantas, la vida es un día, la muerte es un sueño, la vida es un teatro.

Así, por ejemplo, conceptualizar la vida en términos de viaje significa hacer corresponder la estructura del viaje con la de la vida, obteniendo como resultado una reorganización del dominio objeto de tal proyección, que respeta las propiedades y las relaciones típicas del dominio fuente.

Estas proyecciones están estructuradas según correspondencias unidas a la estructura del conocimiento y del razonamiento. La metáfora de la vida como viaje no es por tanto una mera cuestión de palabras, sino que se trata de proyecciones de estructuras conceptuales de un dominio sobre otro. Ello implica que la idea de vida es comprendida en forma de viaje y que modelamos la estructura lógica de la vida sobre la del viaje.

19 George Lakoff - Mark Johnson, Metaphors We Live By, Chicago, The University of Chicago Press, 1981. Cfr. también: George LAKoff, «The Contemporary Theory oh Metaphor», in A. ORTony (ed.), Metaphor and Thought (2nd ed.), Cambridge, Cambridge University Press 1993: 202-251. 
3.3. Podríamos integrar el discurso de Lakoff añadiendo que aunque los procesos de metaforización y de conceptualización son análogos en las diversas culturas, los contenidos que estructuran tales procesos difieren enormemente. Si construir metáforas es un modo de conceptualizarnos a nosotros mismos y nuestro mundo de una manera determinada, proyectando un ámbito sobre otro, no podemos pensar que esto sea diferente a los procesos de formación de la identidad de las diversas culturas. En cierto modo, por tanto, las metáforas que constituirán los perfiles y los límites culturales vienen determinadas por el proceso de diferenciación y segmentación que las culturas realizan en relación o en contraste con otras. Esto significa que no sólo, obviamente, puede tener sentido en la cultura occidental la metáfora de la vida como viaje (pero no tendrá significado en una cultura diferente que no conciba el tiempo en sentido lineal), sino que también metáforas con diversas conceptulizaciones de tiempo constituyen el material imaginativo que las culturas van tejiendo para marcar las fronteras. El paso de un ámbito a otro permite incluso especificar ciertas metáforas centrales en una cultura, que son las que constituirán una identidad marginando y separando algunos aspectos. Así, pues, las metáforas desempeñan un papel fundamental en la identificación de lo que se decide que representa las especificidades culturales, eliminando todos los aspectos híbridos originales. Tal recorrido no es «natural», quiero decir que no describe un valor de partida, sino que se conecta con la necesidad de las culturas de afirmarse diferenciándose entre sí. En otras palabras, las posibilidades del paso de un ámbito a otro son diversas y están expuestas al proceso a través del cual se definen las identidades, proceso que no es ajeno a la ideología.

En este sentido, las metáforas no se pueden reconducir, como he sostenido en otras ocasiones, a un grado cero de la significación. De un modo similar a como pensaba Nietzsche, ${ }^{20}$ podemos decir que la actividad metafórica, que se manifiesta en el lenguaje pero también en otros sistemas, no permite tanto explicar de un modo determinado (un modo figurado, distinto del neutro) el mundo que ya conocemos, cuanto lo vuelve interpretable, ofrece el marco general a través del cual es posible distinguir un orden. Entonces la metáfora no es una envoltura, sino un instrumento indispensable para la construcción de la propia identidad y, como tal, no puede considerarse un sentido indirecto, cuando éste

20 Cfr. Friedrich Nietzsche, Escritos sobre retórica, Trotta, Madrid 2000. 
se interpreta como la imposibilidad de mostrar claramente cualquier sentido directo. Las metáforas recortan, pues, un espacio en el terreno neutro del hibridismo cultural e identifican las fronteras. Son las banderas tras las que se conquistan nuevos territorios y con las que se está en posesión de ellos.

3.4. Las metáforas entonces implican valores importantes en la afirmación de una cultura, circunscriben, por así decirlo, el ámbito del discurso posible y ponen en juego lógicas argumentativas compatibles con el ámbito al que se refieren. Contribuyen a representar las identidades y que éstas se constituyen a través del discurso. La traducción en este caso se convierte en un auténtico acto de crítica o de consenso respecto de la ideología. ${ }^{21}$ La traducción de metáforas en particular es un acto de crítica porque muestra o encubre los mecanismos detrás de los cuales se crean y mantienen las identidades, y puede tanto plantear a debate la historia como justificarla. En este sentido puede ser un acto destructivo o servir para homogeneizarla o manipularla totalmente.

4. Esquilo finaliza Los Persas con el lamento de Jerjes, pero el lamento por la derrota viene precedido por el estupor de la reina Atosa ante la «diversidad» griega. Esquilo hace que tal estupefacción preceda a la llegada del mensajero con la noticia del desastre y de este modo subraya que el motivo de la victoria estriba precisamente en la diferencia griega respecto al que entonces era el único imperio universal. Griegos y persas tienen los mismos dioses y los límites reales entre éstos y aquéllos son imprecisos, sin embargo, los griegos se declaran al margen de los demás pueblos pertenecientes al reino persa, que poseen sus propias tradiciones y lenguas, y marcan una frontera respecto a ellos. Separación, diversidad y frontera. Comienza la historia de la identidad griega, y con ella la de Occidente.

21 Cfr. García Canclini, op. cit., pp. 87-94. 


\section{BiBLIOGRAFÍA}

BНАBHA, H. K.

1994 The Location of Culture, London and New York, Routledge.

Cornejo Polar, Antonio

1994 Escribir en el aire. Ensayo sobre la heterogeneidad socio-cultural en las literaturas andinas, Lima, Editorial Horizonte.

EVEN-ZOHAR, I.

1990 Polysystem Studies, número monográfico de Poetics Today, II, 1.

1995 «La posizione della letteratura tradotta all'interno del polisistema letterario», en S. Nergaard (a cura di), Teorie contemporanee della traduzione, Milano, Bompiani: 225-238.

García CANCLini, Néstor

2001 Culturas híbridas, 1. ${ }^{a}$ edición actualizada, Buenos Aires, Editorial Paidós.

GRASSi, Corrado

1969 «Il concetto di diasistema e i principi della geografia linguistica», en Atti del Convegno Internazionale sul tema: Gli Atlanti Linguistici. Problemi e risultati, Roma, Accademia Nazionale dei Lincei: 271-283.

HALl, Stuart

2002 «A chi serve 'l'identità'?», en C. Bianchi, C. Demaria, S. Nergaard, Spettri del potere, Roma, Meltemi: 129-153.

HEILMANN, Luigi

1965 «Structuralisme et histoire dans le domaine linguistique italien: le vocalisme d'un dialecte typique », en Actes du IX Congrès Internationale de Linguistique et Philologie Romanes, III París.

LAKOFF, George

1993 «The Contemporary Theory oh Metaphor», en A. Ortony (ed.), Metaphor and Thought (2. ${ }^{\mathrm{a}}$ ed.), Cambridge, Cambridge University Press: 202-251.

LAKOFF, G. - Johnson, M.

1981 Metaphors We Live By, Chicago, The University of Chicago Press.

NiETZSCHE, Friedrich

2000 Escritos sobre retórica, Trotta, Madrid.

Toury, Gideon

1995 Descriptive Translation Studies and Beyond, Amsterdam-Philadelphia, Benjamins.

WEINRICH, Uriel

1963 Languages in Contact, l'Aia, Mouto. 